\title{
First and Second Wave COVID-19 Fear Impact: Israeli and Russian Social Work Student Fear, Mental Health and Substance Use
}

\author{
Alexander Reznik ${ }^{1}$ - Valentina Gritsenko ${ }^{2}$ - Vsevolod Konstantinov ${ }^{3}$ - Mor Yehudai ${ }^{1}$. \\ Shmaya Bender ${ }^{1} \cdot$ Irina Shilina ${ }^{4} \cdot$ Richard Isralowitz $^{1}$ (D)
}

Accepted: 29 December 2020 /Published online: 2 February 2021

(C) The Author(s), under exclusive licence to Springer Science+Business Media, LLC part of Springer Nature 2021

The COVID-19 pandemic has caused universities worldwide to limit operation, shift traditional classroom learning to internet instruction, and restrict contact through recommended social distancing (WHO 2020a). Such actions have been taken in spite of a possible mental health tsunami (Carson et al. 2020) resulting from factors of social isolation (Holmes et al. 2020), substance misuse (Gritsenko et al. 2020; Zolotov et al. 2020), and other maladaptive coping mechanisms (Bender et al. 2020; Cheng et al. 2020).

The experience of living in the pandemic has heightened interest in personality factors that may serve as a bulwark against fear, stress and other COVID-19 negative impacts. Psychological resilience, understood as the ability to psychologically or emotionally cope with a crisis or quickly return to a pre-crisis state, is increasingly seen as a protective factor (Barzilay et al. 2020; Walsh 2020; Y1ldırım and Solmaz 2020). Among university students, harmful pandemic effects on psychological and emotional well-being have been observed (McKay and Asmundson 2020). However, few studies have examined the evolution of such effects and resilience among university students with service responsibilities to high risk clientele (Isralowitz et al. 2020; Zolotov et al. 2020).

This study aims to examine COVID-19 related fear and its association with psychoemotional conditions including substance use among Israeli and Russian social work students at two peak points or waves of infection. The first study was conducted in May and the second, including examination of student resilience, in October/November, 2020. It is hypothesized

Richard Isralowitz

Richard@bgu.ac.il

1 Regional Alcohol and Drug Abuse Research Center, Ben Gurion University of the Negev, 84105 Beer Sheva, Israel

2 Department of Social Psychology, Moscow State University of Psychology and Education, Moscow, Russia

3 Department of General Psychology, Penza State University, Penza, Russia

4 Department of Social Communication, Moscow State University of Psychology and Education, Moscow, Russia 
that COVID-19 fear, mental health and substance use differ among university social work students from Israel and Russia; and, self-reported resilience positively influences maladaptive behavior conditions regardless of nationality.

\section{Methods}

\section{Design, Participants, and Procedures}

The Qualtrics software platform was used for this online survey. The main data collection instrument was the seven-item Fear of COVID-19 Scale (FCV-19S) (Ahorsu et al. 2020; Bitan et al. 2020; Reznik et al. 2020). The levels of agreement with FCV-19S statements were evaluated by a 5-point Likert scale from 1 (strongly disagree) to 5 (strongly agree). Higher total scores correspond with more COVID-19 fear. Two questions were added to the scale to determine COVID-19 impact on university student studies, social life, and family relations.

Fear levels, based on scale responses close to a normal distribution (skewness $=0.467$; kurtosis $=-0.120$ ), were divided into three parts of $33 \%$ each. This allowed us to report three levels of student COVID-19 fear-low, medium, and high.

A six-item Brief Resilience Scale (BRS) (Smith et al. 2008) was used to determine the level of psychological resilience among Israeli and Russian students. The BRS items assess respondents' ability to bounce back or recover from stress. The levels of agreement with BRS statements were evaluated by a 5-point Likert scale from 1 (strongly disagree) to 5 (strongly agree) for items 1, 3, and 5, and from 5 (strongly disagree) to 1 (strongly agree) for items 2, 4, and 6. Higher total scores correspond with a higher level of resilience. The distribution of the BRS values was divided into three parts. Scale values corresponding to $25 \%$ of the distribution, left side, were interpreted as low resilience, values corresponding to $50 \%$ of the central part of the distribution were interpreted as normal resilience, and values corresponding to $25 \%$ of the distribution, right side, were interpreted as high resilience (Smith 2020).

The Cronbach's reliability of the FCV-19S with two additional questions is 0.827 . The McDonald's Omega score for the FCV-19S is 0.845. The Cronbach's reliability of the BRS is 0.762; and, the McDonald's Omega score for the BRS is 0.798 .

The influence of COVID-19 on student mental health (i.e., depression, exhaustion, loneliness, nervousness and anger) as well as substance use including tobacco, alcohol, and cannabis was examined. The survey instruments, prepared in English, were translated to Hebrew and Russian and back translated. The translation method used is consistent with that described by the World Health Organization for research purposes (WHO 2020b). The Hebrew and Russian versions of the instruments appearing on the Qualtrics platform are available on request from the corresponding author of this article.

To ensure the methods proposed for this research were ethical, the Israeli and Russian investigators received approval from the ethics committees of the universities involved. These ethics approval processes are equivalent to established regulations to help protect the rights and welfare of human research subjects (Breault 2006). No external grant funding was received for the study.

The universities involved in this study conduct distance learning linking students, lecturers, and departments. This capacity was used for data collection. Students in both countries were informed about the online survey. Before responding to the survey questions, the survey aim was explained 
along with assurance of response confidentiality and compliance with all ethical standards. Students were informed their responses to the survey constituted consent to participate in the survey.

\section{Statistical Analysis}

For this study, all statistical analyses were conducted using SPSS, version 25, and JASP, a free and open-source program for statistical analysis supported by the University of Amsterdam (JASP 2020). The Pearson's chi-square test for dichotomous variables, $t$ test, two- and threeway ANOVA for continuous variables were used.

\section{Participants}

A total of 291 social work students from Israel ( $n=170 ; 151$ females, 16 males, 3 other) and Russia ( $n=121$; 91 females, 30 males) completed the on-line questionnaire used during the first wave of COVID-19 infection in May (T1). For comparison purposes, the survey was repeated in November (T2) during a second wave of infection with 388 respondents from Israel ( $n=132 ; 117$ females, 15 males) and Russia ( $n=256$; 192 females, 64 males). Students involved in both surveys included 63 from Israel and 46 from Russia. Table 1 provides background characteristics of the survey respondents for T1 and T2.

\section{Results}

The mean fear score of the FCV-19S at the two points of study are: T1-22.3 (SD = 6.1) and $21.6(\mathrm{SD}=6.6)$ among the Israeli and Russian students (n.s.) and, T2 - respectively, 22.6 $(\mathrm{SD}=5.8)$ and $21.8(\mathrm{SD}=6.4)$ (n.s.). Three-way ANOVA for gender, country, and infection wave interactions evidence no significant differences in fear values $\left(\mathrm{F}_{1,623}=0.958 ; p=0.328\right)$. Therefore, further analysis was conducted with men and women combined as one group.

Two-way ANOVA results evidence no significant change in fear values among the T1 and $\mathrm{T} 2$ students from the two countries $\left(\mathrm{F}_{1,630}=0.021 ; p=0.866\right)$. Also, two-way ANOVA results show no significant change in fear values between $\mathrm{T} 1$ and $\mathrm{T} 2$ students who participated in both surveys from the two countries $\left(\mathrm{F}_{1,368}=0.614 ; p=0.434\right)$.

Table 1 Student demographics characteristics

\begin{tabular}{|c|c|c|c|c|c|c|}
\hline & \multicolumn{3}{|c|}{ First wave (T1) } & \multicolumn{3}{|c|}{ Second wave (T2) } \\
\hline & $\begin{array}{l}\text { Israel } \\
(n=170)\end{array}$ & $\begin{array}{l}\text { Russia } \\
(n=121)\end{array}$ & $\begin{array}{l}\text { Total } \\
(n=291)\end{array}$ & $\begin{array}{l}\text { Israel } \\
(n=132)\end{array}$ & $\begin{array}{l}\text { Russia } \\
(n=256)\end{array}$ & $\begin{array}{l}\text { Total } \\
(n=388)\end{array}$ \\
\hline Gender, \% (n) & $* * *$ & $* * *$ & & $* *$ & $* *$ & \\
\hline Female & $88.8(151)$ & $75.2(91)$ & $83.2(242)$ & $88.6(117)$ & $75.0(192)$ & $79.6(309)$ \\
\hline Male & $9.4(16)$ & $24.8(30)$ & $15.8(46)$ & $11.4(15)$ & $25.0(64)$ & $20.4(79)$ \\
\hline Other & $1.8(3)$ & $0.0(0)$ & $1.0(3)$ & $\begin{array}{l}0.0(0) \\
* * *\end{array}$ & $\begin{array}{l}0.0(0) \\
* * *\end{array}$ & $0.0(0)$ \\
\hline Age, Mean (SD) & $24.9(2.2)$ & $23.7(8.1)$ & $24.4(5.5)$ & $25.6(3.8)$ & $20.0(2.0)$ & $22.7(4.1)$ \\
\hline Median & 25.0 & 21.0 & 24.0 & 25.0 & 20.0 & 22.0 \\
\hline Range & $(19-39)$ & $(17-57)$ & $(17-57)$ & $(19-47)$ & $(17-34)$ & $(17-47)$ \\
\hline
\end{tabular}

$* * p<.01 ; * * * p<.001$ ( $t$ test for age; Chi-square test for gender) 
At the first wave of COVID-19 infection (T1), the percentages of Israeli students reporting more cigarette smoking and alcohol use than usual were 23.6 and $32.6 \%$. At the time of second wave infection (T2), no significant increase was reported for COVID-related smoking (20.2\%) and alcohol (26.1\%) use. Among Russian students, the level of COVID-19 related cigarette use remained stable (13.0\% vs $13.3 \%$ ) during T1 and T2 periods; however, the percentage of Russian students reporting increased alcohol use dropped from $25.0 \%$ (T1) to $13.3 \%$ (T2) $(p<.01)$. Over the T1 to T2 periods, no significant increase of binge drinking was found among the Israeli (10.8\% vs. $12.7 \%)$ and Russian (14.2\% vs. $9.6 \%)$ students.

T1 survey results show no significant difference of COVID-19 fear values associated with substance use among Israeli and Russian students. However, T2 results evidence a change of fear values and alcohol use $\left(\mathrm{F}_{1,332}=11.999 ; p=0.001\right)$ (Fig. 1). Israeli students who report not using alcohol during the past month evidence lower levels of fear compared with those who used alcohol. Russian students who drink have a lower level of fear than those who do not use alcohol.

T1 and T2 findings show COVID-19 fear linked to levels of depression, exhaustion, loneliness, nervousness, and anger. In most cases, students from both countries reported a decrease of problem psycho-emotional conditions, especially those from Russia (see Table 2). Table 3 presents the findings of the same students who participated in the first- and secondwave surveys. For these students, most psycho-emotional problem conditions remained stable with some, non-significant improvement.

Regardless of country, students who reported COVID-19 associated with their psychoemotional well-being had higher fear values $\left(\mathrm{T} 1-\mathrm{t}_{239}=5.823 ; p<.001\right.$; for $\mathrm{T} 2-\mathrm{t}_{315}=7.143$; $\mathrm{p}<.001)$. However, T1 and T2 results show no significant change in the extent of association between fear value and psycho-emotional conditions over the two survey periods $\left(\mathrm{F}_{1,554}=\right.$ $0.410 ; p=0.522)$.

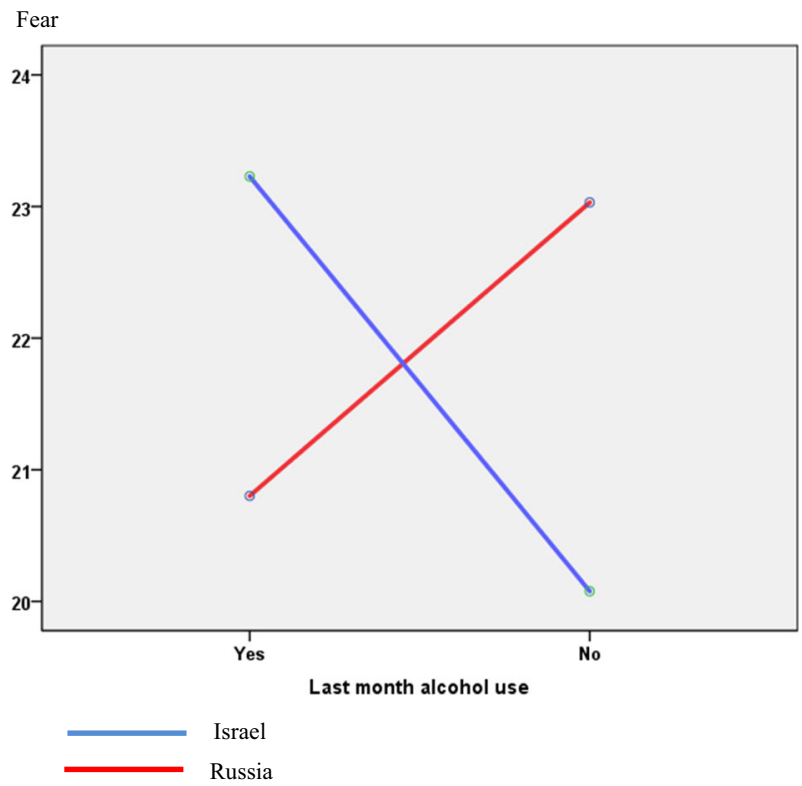

Fig. 1 Fear of COVID-19 by country and last month alcohol use 
Table 2 Psycho-emotional states by wave and country

\begin{tabular}{llllll}
\hline COVID-19 Fear & \multicolumn{2}{l}{ Israel } & & \multicolumn{2}{l}{ Russia } \\
\cline { 2 - 3 } \cline { 5 - 6 } & $\begin{array}{l}\text { First wave } \\
(n=170)\end{array}$ & $\begin{array}{l}\text { Second wave } \\
(n=132)\end{array}$ & & $\begin{array}{l}\text { First wave } \\
(n=121)\end{array}$ & $\begin{array}{l}\text { Second wave } \\
(n=256)\end{array}$ \\
\hline Depressed, \% (n) & $45.3(68)$ & $42.0(50)$ & & $46.4(52)^{* *}$ & $30.2(65)^{* *}$ \\
Exhausted, \% (n) & $63.1(94)$ & $53.8(64)$ & & $35.8(38)^{* *}$ & $19.9(43)^{* *}$ \\
Lonely, \% (n) & $66.0(99)$ & $54.2(64)$ & & $48.6(51)^{* *}$ & $31.0(66)^{* *}$ \\
Nervous, \% (n) & $46.7(70)^{*}$ & $33.6(40)^{*}$ & & $50.9(58)^{*}$ & $36.8(81)^{*}$ \\
Angry, \% (n) & $42.3(63)$ & $50.8(60)$ & & $44.2(46)^{* *}$ & $28.8(61)^{* *}$ \\
\hline
\end{tabular}

$* p<.01 ; * * p<.001$ (Chi-square test)

Distribution of the BRS values is close to normal (Mean 19.1 ( $\mathrm{SD}=3.9$ ); Median 19.0; skewness $=-0.124$; kurtosis $=0.258)$. Values from 6 to 17 indicate low $(n=104), 18$ to 21 normal $(n=145)$ and 22 to 30 high resilience levels.

Israeli and Russian students reported significantly different resilience levels: Mean 19.7 $(\mathrm{SD}=4,0)$ vs. Mean $18.8(\mathrm{SD}=3.9)$ respectively; $\mathrm{t}_{337}=2.127 ; p=.034$. However, regardless of country, higher values of resilience corresponded to lower COVID-19 fear levels and psycho-emotional problems (Table 4).

\section{Discussion}

The COVID-19 pandemic continues to affect people and many sectors of society. In mid-December (2020), more than 2,821,000 Russians and 373,655 Israeli were infected (Johns Hopkins University of Medicine 2020). While there is much hope for a medical breakthrough, it seems much more will be needed to overcome the devastation caused in such a brief time period.

The present study is, to the best of our knowledge, the first cross-national investigation of COVID-19 fear and its association with the mental health, substance use, and resilience over time among university social work students. Psycho-emotional conditions of fear, depression, exhaustion, loneliness, nervousness and anger, as well as smoking and binge drinking among Israeli students surveyed in May (T1) and October/November (T2) remained mostly unchanged; however, such conditions significantly improved among those from Russia.

Overall, present study results evidence signs of resilience and coping among Israeli and Russian students toward COVID-19 conditions. However, for T2, a difference was found associated with last month alcohol use and level of student fear. Israeli social work students

Table 3 Psycho-emotional states by wave and country for students who involved in both surveys

\begin{tabular}{|c|c|c|c|c|}
\hline \multirow[t]{2}{*}{ COVID-19 Fear } & \multicolumn{2}{|l|}{ Israel } & \multicolumn{2}{|l|}{ Russia } \\
\hline & $\begin{array}{l}\text { First wave } \\
(n=170)\end{array}$ & $\begin{array}{l}\text { Second wave } \\
(n=63)\end{array}$ & $\begin{array}{l}\text { First wave } \\
(n=121)\end{array}$ & $\begin{array}{l}\text { Second wave } \\
(n=46)\end{array}$ \\
\hline Depressed, \% (n) & $45.3(68)$ & $47.8(22)$ & $46.4(52)$ & $44.2(19)$ \\
\hline Exhausted, \% (n) & $63.1(94)$ & $60.9(28)$ & $35.8(38)$ & $38.6(17)$ \\
\hline Lonely, \% (n) & $66.0(99)$ & $60.0(27)$ & $48.6(51)$ & 41.5 (17) \\
\hline Nervous, \% (n) & $46.7(70)$ & $32.6(15)$ & $50.9(58)$ & $35.7(15)$ \\
\hline Angry, \% (n) & $42.3(63)$ & $53.3(24)$ & $44.2(46)$ & $38.1(16)$ \\
\hline
\end{tabular}


Table 4 Resilience association with fear and psycho-emotional states

\begin{tabular}{llll}
\hline & \multicolumn{2}{l}{ Level of resilience } & \\
\cline { 2 - 4 } & $\begin{array}{l}\text { Low } \\
(n=104)\end{array}$ & $\begin{array}{l}\text { Medium } \\
(n=145)\end{array}$ & $\begin{array}{l}\text { High } \\
(n=90)\end{array}$ \\
\hline Fear of COVID-19, Mean (SD) & $24.5(6.4)^{* * *}$ & $22.0(5.6)^{* * *}$ & $19.7(5.6)^{* * *}$ \\
Depressed, \% (n) & $53.9(55)^{* * *}$ & $26.1(36)^{* * *}$ & $25.0(22)^{* * *}$ \\
Exhausted, \% (n) & $43.0(43)^{*}$ & $25.7(36)^{*}$ & $30.3(27)^{*}$ \\
Lonely, \% (n) & $56.6(56)^{* * *}$ & $31.2(43)^{* * *}$ & $33.0(29)^{* * *}$ \\
Nervous, \% (n) & $58.0(58)^{* * *}$ & $31.5(45)^{* * *}$ & $18.0(16)^{* * *}$ \\
Angry, \% (n) & $48.5(47)^{* *}$ & $29.2(40)^{* *}$ & $34.4(31)^{* *}$ \\
\hline
\end{tabular}

$* p<.05 ; * * \mathrm{p}<.01 ; * * * p<.001$ ( $t$ test for fear; Chi-square test for other)

who did not use alcohol during the past month prior to the survey had lower COVID-19 fear levels. For Russian students, the situation is reversed. Those who drank had a lower level of fear. Alcohol use, therefore, may be a more significant means of reducing COVID-19 fear by Russian, than Israeli, students. Further research is needed to better understand this difference and implications linked to possible misuse.

Changes in teaching/learning format, personal health and that of family and friends, lack of reliable and consistent COVID-19 information, and diminished social contact and support tend to be predictors of high stress levels, depression, anxiety and other psycho-emotional problems among university students, especially females (Fitzpatrick et al. 2020; Gritsenko et al. 2020; Lai et al. 2020; Liu et al. 2020; Yehudai et al. 2020). Insignificant differences were found among the survey respondents based on gender status. However, the social work profession has a high rate of female students and personnel meaning support and intervention may be needed to mitigate personal and professional needs resulting from their role associated with COVID-19 conditions.

\section{Limitations}

The present study has limitations. First, an online survey makes it difficult to generate random samples since the respondents are only those who use the Internet. Such sampling weakens generalizability of the study findings, and survey participants do not have the opportunity to ask clarifying questions. Second, we examined two cross-sectional data sources by comparing T1 and $\mathrm{T} 2$ results and assessing differences. Only 109 students were involved in both surveys limiting an understanding of the extent of change that may have occurred over the two study points and the ability to draw relevant conclusions. Third, further investigation over time and across locations, is needed to better understand the association of COVID-19 fear, mental health, substance use and resilience among students addressing pandemic and other disaster conditions.

To address this limitation, it is suggested that additional cross-nation study be considered, especially among researchers who have used the fear of COVID 19 scale (Ahorsu et al. 2020). This will provide the opportunity to promote uniform data collection and information sharing among a broad network of colleagues about the impact of COVID-19 fear. Also, consideration is warranted to expand the present study to medical and allied health (e.g., emergency medical services) students and professional personnel, especially first-line responders and those addressing the needs of vulnerable populations including the elderly. 
Acknowledgments Gratitude is expressed to Drs. Toby and Mort Mower for their generous support of the Ben Gurion University of the Negev-Regional Alcohol and Drug Abuse Research (RADAR) Center.

\section{Compliance with Ethical Standards}

Conflict of Interest The authors declare that they have no conflict of interest.

Ethics The authors of this article declare compliance with ethical standards.

\section{References}

Ahorsu, D. K., Lin, C. Y., Imani, V., Saffari, M., Griffiths, M. D., \& Pakpour, A. H. (2020). The fear of COVID19 scale: development and initial validation. International journal of Mental Health and Addiction. https:// doi.org/10.1007/s11469-020-00270-8.

Barzilay, R., Moore, T. M., Greenberg, D. M., DiDomenico, G. E., Brown, L. A., White, L. K., \& Gur, R. E. (2020). Resilience, COVID-19-related stress, anxiety and depression during the pandemic in a large population enriched for healthcare providers. Translational Psychiatry, 10(1), 1-8.

Bender, S., Florentine, E., \& Isralowitz, R. (2020). Medical students on the front line of COVID 19. Journal of Loss and Trauma, 1-3. https://doi.org/10.1080/15325024.2020.1808362.

Bitan, D. T., Grossman-Giron, A., Bloch, Y., Mayer, Y., Shiffman, N., \& Mendlovic, S. (2020). Fear of COVID19 scale: Psychometric characteristics, reliability and validity in the Israeli population. Psychiatry Research, 113100, 113100. https://doi.org/10.1016/j.psychres.2020.113100.

Breault, J. L. (2006). Protecting human research subjects: The past defines the future. The Ochsner Journal, 6(1), $15-20$.

Carson, J., Eyre, H., \& Lavretsky, H. (2020). Dear mental health innovators: The COVID-19 honeymoon is almost over. Psychiatric time. Retrieved from https:/www.psychiatrictimes.com/article/dear-mental-healthinnovators-covid-19-honeymoon-almost-over.

Cheng, C., Ebrahimi, O. V., \& Lau, Y. C. (2020). Maladaptive coping with the infodemic and sleep disturbance in the COVID-19 pandemic. Journal of Sleep Research, e13235. https://doi.org/10.1111/jsr.13235.

Fitzpatrick, K. M., Harris, C., \& Drawve, G. (2020). Fear of COVID-19 and the mental health consequences in America. Psychological Trauma: Theory, Research, Practice, and Policy, 12(S1), S17-S21. https:/doi.org/ $10.1037 /$ tra0000924.

Gritsenko, V., Skugarevsky, O., Konstantinov, V., Khamenka, N., Marinova, T., Reznik, A., \& Isralowitz, R. (2020). COVID 19 fear, stress, anxiety, and substance use among Russian and Belarusian university students. International Journal of Mental Health and Addiction, 1. https://doi.org/10.1007/s11469-020$00330-\mathrm{z}$

Holmes, E. A., O'Connor, R. C., Perry, V. H., Tracey, I., Wessely, S., Arseneault, L., et al. (2020). Multidisciplinary research priorities for the COVID-19 pandemic: A call for action for mental health science. The Lancet Psychiatry, 7(6), 547-560. https://doi.org/10.1016/S2215-0366(20)30168-1.

Isralowitz, R., Khamenka, N., Konstantinov, V., Gritsenko, V., \& Reznik, A. (2020). Fear, depression, substance misuse and related conditions among multi-national medical students at the peak of the COVID-19 epidemic. Journal of Loss and Trauma, 1-4. https://doi.org/10.1080/15325024.2020.1799521.

JASP. (2020). A Fresh Way to Do Statistics. Retrieved from https://jasp-stats.org/

Johns Hopkins University of Medicine. (2020). Coronavirus Resource Center. Retrieved from https:// coronavirus.jhu.edu/map.html.

Lai, Y. K. A., Lee, L., Wang, M. P., Feng, Y., Lai, T. T., Ho, L. M., et al. (2020). Mental health impacts of the COVID-19 pandemic on international university students, related stressors, and coping strategies. Frontier in Psychiatric.

Liu, N., Zhang, F., Wei, C., Jia, Y., Shang, Z., Sun, L., Wu, L., Sun, Z., Zhou, Y., Wang, Y., \& Liu, W. (2020). Prevalence and predictors of PTSS during COVID-19 outbreak in China hardest-hit areas: gender differences matter. Psychiatry Research, 112921, 112921. https://doi.org/10.1016/j.psychres.2020.112921.

McKay, D., \& Asmundson, G. J. G. (2020). COVID-19 stress and substance use: current issues and future preparations. Journal of Anxiety Disorders., 74, 102274. https://doi.org/10.1016/j.janxdis.2020.102274.

Reznik, A., Gritsenko, V., Konstantinov, V., Khamenka, N., \& Isralowitz, R. (2020). COVID-19 fear in Eastern Europe: validation of the fear of COVID-19 scale. International Journal of Mental Health and Addiction, 1. https://doi.org/10.1007/s11469-020-00283-3.

Smith, B. W. (2020). User guide for the stress adaptation scale. Personal communications. 
Smith, B. W., Dalen, J., Wiggins, K., Tooley, E., Christopher, P., \& Bernard, J. (2008). The brief resilience scale: Assessing the ability to bounce back. International Journal of Behavioral Medicine, 15(3), 194-200.

Walsh, F. (2020). Loss and resilience in the time of COVID-19: Meaning making, hope, and transcendence. Family Process, 59(3), 898-911.

World Health Organization (WHO). (2020a). Coronavirus disease (COVID-19) advice for the public. Retieved from https://www.who.int/emergencies/diseases/novel-coronavirus-2019/advice-for-public\#: :text= Maintain\%20at\%20least\%20a\%201,of\%20being\%20around\%20other\%20people.

World Health Organization (WHO). (2020b). Process of translation and adaptation of instruments. Retrieved from https://www.who.int/substance_abuse/research_tools/translation/en/

Yehudai, M., Bender, S., Gritsenko, V., Konstantinov, V., Reznik, A., \& Isralowitz, R. (2020). COVID-19 fear, mental health, and substance misuse conditions among university social work students in Israel and Russia. International Journal of Mental Health and Addiction, 1-8. https://doi.org/10.1007/s11469-020-00360-7.

Yıldırım, M., \& Solmaz, F. (2020). COVID-19 burnout, COVID-19 stress and resilience: Initial psychometric properties of COVID-19 burnout scale. Death Studies, 1-9. https://doi.org/10.1080/07481187.2020. 1818885.

Zolotov, Y., Reznik, A., Bender, S., \& Isralowitz, R. (2020). COVID-19 fear, mental health, and substance use among Israeli university students. International Journal of Mental Health and Addiction, 1-7. https://doi. org/10.1007/s11469-020-00351-8.

Publisher's Note Springer Nature remains neutral with regard to jurisdictional claims in published maps and institutional affiliations. 